\title{
Outcomes of transcutaneous aortic valve replacement among high risk WV population
}

\author{
George M. Yousef, MD'1', Julia Poe, BA ${ }^{1}$, Cameron Killmer, BS ${ }^{1}$, \\ Basel Edris, MD', Jason Mader, DO', Ellen A. Thompson, MD', \\ Daniel Snavely, MD², Silvestre Cansino, MD', Joseph I. Shapiro, MD', \\ Mark A. Studeny, MD ${ }^{1}$
}

ABSTRACT

INTRODUCTION: Transcatheter aortic valve replacement (TAVR) is a relatively new strategy for replacing the aortic valve. We elected to review our early experience to see if we could identify clinical characteristics at baseline or immediately following the procedure that would predict death within one year.

METHOds: Charts for all patients assigned to receive TAVR procedure at St Mary's Medical Center, Huntington, West Virginia between April 2013 and November 2016 were identified and reviewed. A total of seventy-two cases were included.

ResULts: All-cause mortality rate at index hospitalization, 30 days, and 12 months was $5.6 \%(\mathrm{~N}=4), 6.9 \%(\mathrm{~N}=5), 19.4 \%(\mathrm{~N}=14)$ respectively. Stroke rate at index hospitalization, 30 days, and 12 months was $2.8 \%(\mathrm{~N}=2), 2.8 \%(\mathrm{~N}=2), 8.3 \%(\mathrm{~N}=6)$ respectively. Major predictors of death were post procedure GFR, contrast volume, and number of antiplatelet agents therapy $(\mathrm{AUC}=0.638,0.632,0.637$ respectively).

CONCLUSION: We found that post procedure GFR, less number of antiplatelet agents post procedure, and contrast volume may predict mortality within first 12 months post TAVR. Further studies focused on the above factors may be warranted.
Author affiliations are listed at the end of this article.

Correspondence to: George M. Yousef, MD Marshall University Joan C. Edwards School of Medicine yousef@marshall.edu

\section{KEYWORDS}

transcathether, aortic valve, percutaneous, mortality, hypertension, blood pressure, correlation, machine learning

\section{INTRODUCTION}

Transcatheter aortic valve replacement (TAVR) is a relatively new strategy for replacing the aortic valve in patients with severe aortic stenosis (AS) who are felt to be at significant or prohibitive risk for conventional surgical approach. 1 The positive results from various randomized controlled trials (RCTs) led to rapid evolution of the procedure.2-4 Both balloonexpandable and self-expandable valves showed comparable results as compared to surgical aortic valve replacement (SAVR).2, 3 Recently the procedure was approved to include intermediate surgical risk patients based on PARTNER 2 cohort. ${ }^{4}$ Although the very definition of the high risk population predicts a high mortality rate, we elected to review our early experience after performing more than 50 TAVR procedures to see if we could identify clinical characteristics at baseline or immediately following the procedure that would predict early death (death within one year) in our high risk population. To facilitate such identification, we chose to employ various machine learning methods effective in predicting categorical outcomes. ${ }^{5}$ 


\section{METHODS}

Charts of all patients assigned to receive TAVR procedure at St Mary's Medical Center, Huntington, West Virginia between April 2013 and November 2016 were identified and reviewed. A total of 72 high-risk cases were included. One of these patients died prior to undergoing the procedure. Pre-procedural, procedural, and post-procedural data were obtained and analyzed. The baseline characteristics of these patients are shown in Table 1. Primary outcomes were identified as all cause mortalities and strokes at index hospitalization, 30 days, and 12 months. Secondary outcomes data were identified as access site complications, heart failure symptoms, renal failure, length of stay, and postprocedural valvular hemodynamics.

\section{STATISTICAL ANALYSIS}

All analysis was performed using the open source program $R$. The data was cleaned by excluding variables with large numbers of missing values. Variables with more moderate amounts of missing values that had numeric data had the average value placed into missing value categories. Analysis of 72 subjects was then possible. Machine learning was performed on a dataset without missing values. Parameters used for subsequent analysis are shown in Table 1. Before deciding to analyze the dataset without missing values, multiple methods of imputation for both missing categorical and continuous data were employed and yielded results similar to analysis on the cleansed data.

\section{Logistic Regression and Support Vector Machine}

\begin{tabular}{|c|c|}
\hline Characteristic & TAVR $(\mathrm{N}=72)$ \\
\hline Age-yr & $80.4 \pm 8.7$ \\
\hline Male sex-no. (\%) & $38(53)$ \\
\hline STS score & $10.4 \pm 6.2$ \\
\hline NYHA Class III or IV no. (\%) & $69(95.8)$ \\
\hline KCCQ 12 & $29.6 \pm 11.6$ \\
\hline \multicolumn{2}{|l|}{ Coronary artery disease - no. (\%) } \\
\hline - One vessel & $19(26.3)$ \\
\hline - Two vessels & $10(13.8)$ \\
\hline - Three vessels & $8(11.1)$ \\
\hline Previous CABG-no. (\%) & $20(27.7)$ \\
\hline Previous PCI-no. (\%) & $20(27.7)$ \\
\hline $\begin{array}{l}\text { PCI within } 30 \text { days prior procedure - no. } \\
(\%)\end{array}$ & $5(6.9)$ \\
\hline Cerebrovascular disease--no. (\%) & $22(30.5)$ \\
\hline Peripheral vascular disease--no. (\%) & $35(48.6)$ \\
\hline Diabetes Mellitus --no. (\%) & $28(38.8)$ \\
\hline Hypertension-no. (\%) & $71(98.6)$ \\
\hline COPD-no. (\%) & $53(73.6)$ \\
\hline Oxygen dependent - no. $(\%)$ & $20(27.7)$ \\
\hline Pre procedure GFR & $56.3 \pm 23.0$ \\
\hline Atrial fibrillation - no. (\%) & $16(22.2)$ \\
\hline $1^{\text {st }}$ Degree AVB —no. $(\%)$ & $15(20.8)$ \\
\hline RBBB-no. (\%) & $13(18)$ \\
\hline PPM/AICD - no. $(\%)$ & $13(18)$ \\
\hline Aortic Valve Area - $\mathrm{CM}^{2}$ & $0.72 \pm 0.18$ \\
\hline Mean Gradient $-\mathrm{mmHg}$ & $51.1 \pm 12.2$ \\
\hline Left Ventricular Ejection Fraction - (\%) & $48.4 \pm 12.4$ \\
\hline $\begin{array}{l}\text { Moderate or Severe mitral regurgitation - } \\
\text { no. }(\%)\end{array}$ & $16(22.2)$ \\
\hline Mitral stenosis - no. (\%) & $15(20.8)$ \\
\hline
\end{tabular}

TABLE 1: Baseline patient characteristics
We used a generalized linear (logistic regression) model as our default ${ }^{6}$ using only baseline variables for the prediction of composite endpoint outcomes. In addition, we examined the utility of a support vector machine (SVM) which involves the multidimensional sorting of data based on the development of a hyperplane which best segregates the two classes. ${ }^{8}$ Using the CARET package, we employed two tuning parameters to control the performance of the SVM: kernel and C. We used the radial kernel option from the CARET package. When radial kernel is applied, Sigma needs to be specified to avoid over-fitting. The second tuning parameter used was $C$ which specifies the penalty for misclassification. The best combination of $C$ and Sigma values are determined using crossvalidation. Sigma and $C$ values were optimized within the CARET package, and values of $1 \mathrm{e}-4$ and 32 were used thereafter.

RANDOM FOREST 
The third method we applied is the random forest which employs decision trees to construct a predictive model using a set of binary rules applied to calculate a target value. We used two tuning parameters for random forest: the number of trees (ntree) averaged (1000) and the number of variables (mtry $=9$ ) randomly sampled as candidates at each split in each tree. The mtry parameter was varied and optimized using the ROC on the training set. ${ }^{7.8}$

\section{Neural Network}

We also tried a feed-forward neural network. Different feed forward neural network architectures were explored using the nnet and neuralnet packages. ${ }^{9}$ We found optimal performance with one hidden layer containing 9 hidden neurons with a decay value 0.24 after initial exploration.

\section{Model Comparisons}

The CARET package was used for comparison of the mature models employing 10 folds and 3 repeats. ${ }^{10}$ Other packages within $\mathrm{R}$ were used for different specific tasks (e.g., nnet for construction of the neural network, random forest (randomForest) for constructing random forests). ${ }^{9,11-15}$ All numeric data were centered and scaled prior to analysis with all of the above methods. The $\mathrm{R}$ code used for these analyses is shown in appendix 1.

\section{Training and Test Sets}

In the first phase, we varied tuning parameters on a training subset with the CARET package. For the support vector machine, the sigma and $c$ values were varied from 0.1 to 1 . Once these parameters were optimized for the different methods, we used different seed values to split the training and testing sets (50\% training:50\% testing). We then employed the strategy of 3 repeats of the 10 folds with CARET on the different training subsets achieved varying the seed to initiate randomization to divide the set into training and testing subsets.

\section{RESULTS}

A total of 72 patients underwent TAVR. One patient died before getting the assigned procedure. Transfemoral access was $88.9 \%(\mathrm{~N}=64)$, Transapical access was $11.1 \%(\mathrm{~N}=8)$. The characteristics of the patients at baseline are shown in Table 1. Valve types used are shown in Table 2.

\begin{tabular}{|l|c|}
\hline \multicolumn{1}{|c|}{ Valve Type } & Number \\
\hline Sapien & 38 \\
\hline Sapien XT & 20 \\
\hline CoreValve & 10 \\
\hline Sapein 3 & 4 \\
\hline
\end{tabular}

TABLE 2: Valve types

Death and Stroke

Death rate from any cause at 12 months was $19.4 \%(\mathrm{~N}=14)$ of which $4(5.6 \%)$ died during index hospitalization and one (1.3\%) at 30 days. Stroke incidence at 12 months was $8.3 \%(\mathrm{~N}=6)$ of which two patients $(2.8 \%)$ had stroke during index hospitalization, no new cerebrovascular events at 30 days.

Major multivariate predictors of death from any cause at 12 months are presented in Table 3 and Figure 1. Comparison of those with and without early death ( $<12$ months) is shown in Table 4.

\section{Procedure outcomes}

The procedure was aborted in one patient due to inability to pass the valve through transfemoral approach. Patient died before getting transapical approach. None of the patients required conversion to open surgical approach. A total of 5 (6.9\%) 


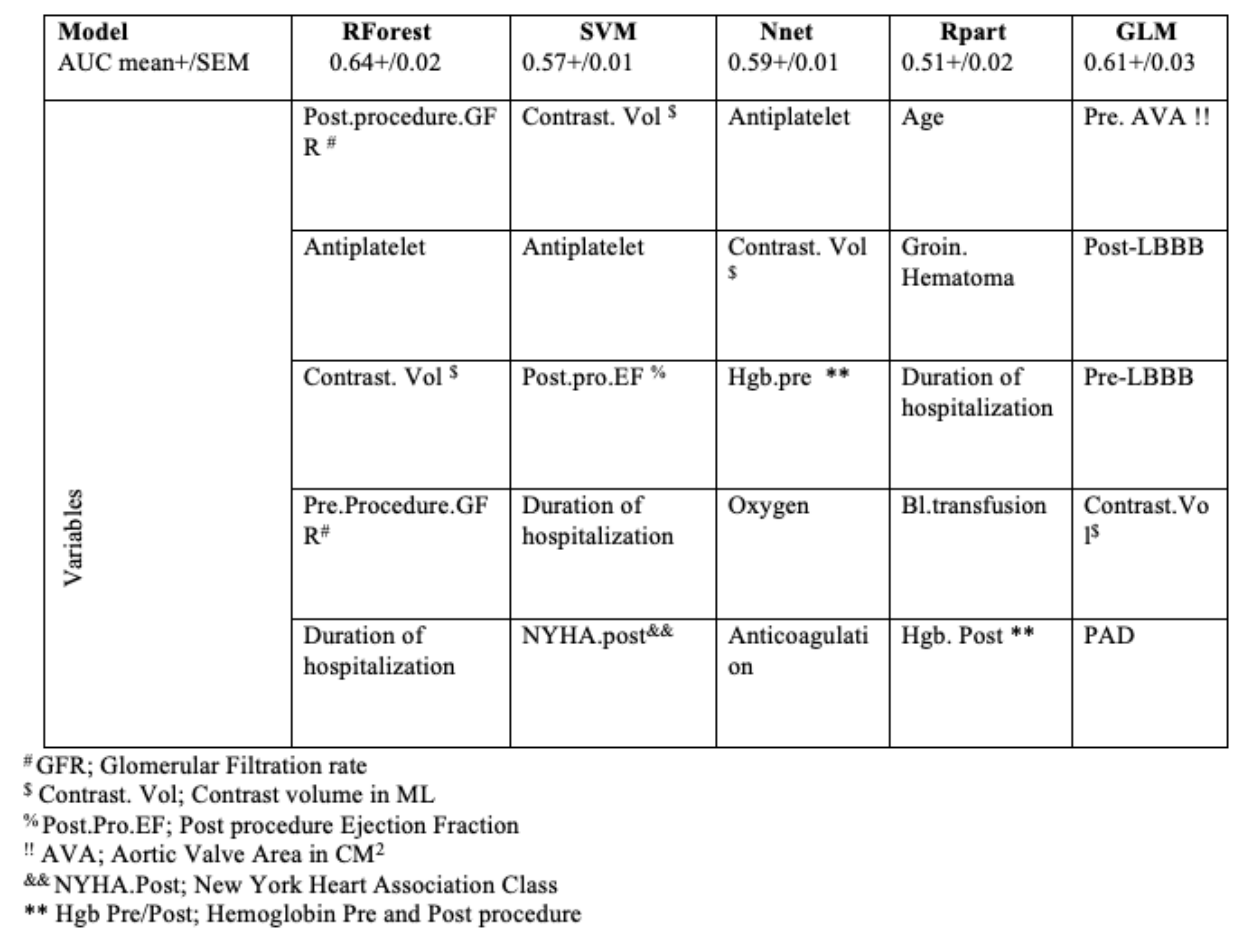

TABLE 3: Mean and Standard Error of Mean (SEM) of Receiver Operator Curve (ROC) values utilizing different techniques. Top five predictor variables of death at 12 months.

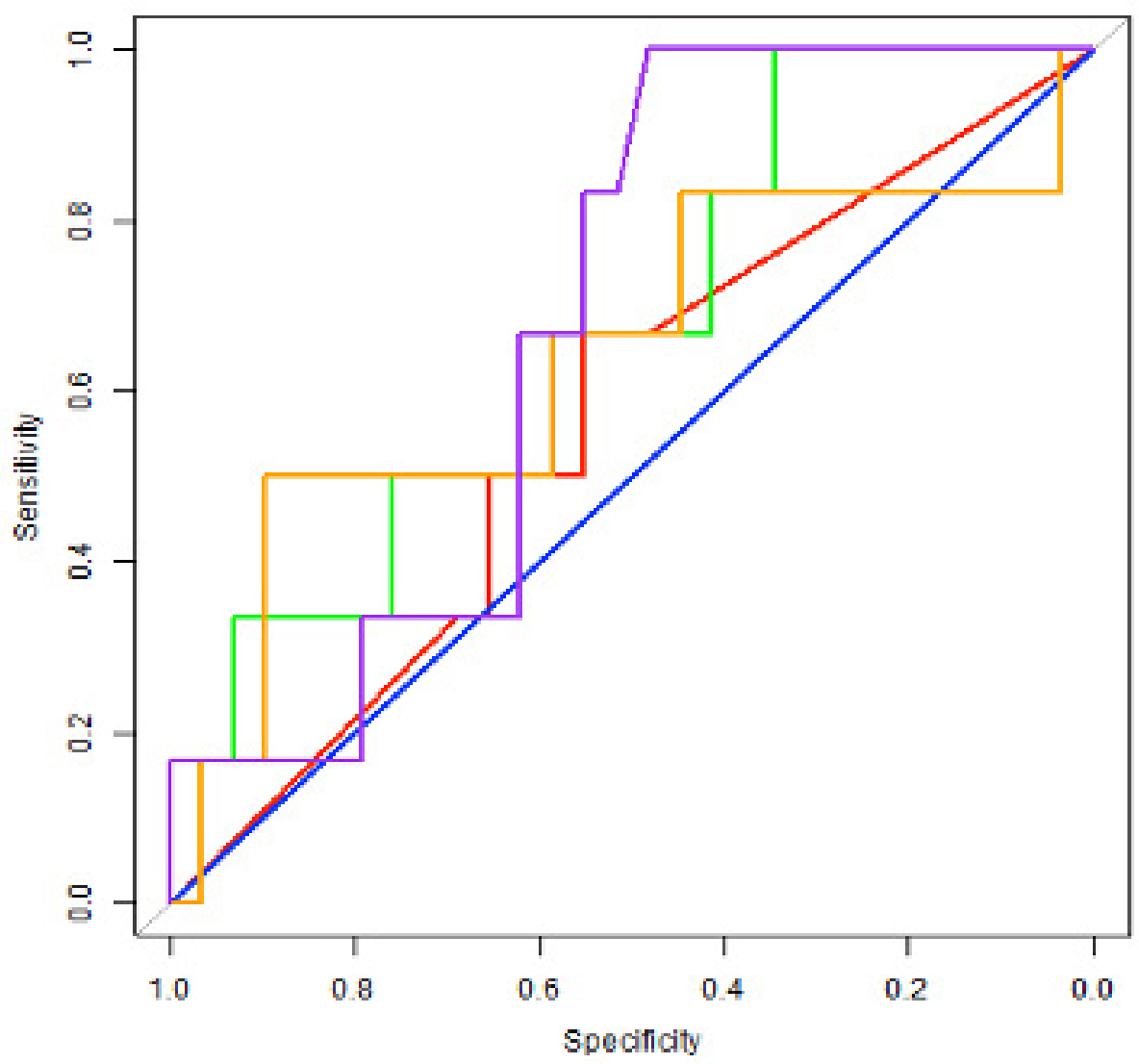

FIGURE 1: Receiver operator curves (ROC) in one of the techniques showing sensitivity against specificity for generalized linear model (GLM)

- red color, area under curve (AUC) $=0.56$, support vector machine (SVM)

- green color, $A \cup C=0.63$, neural network (NNet)

- orange color, $A \cup C=0.63$, random forest (RFor)

- purple color, $A \cup C=0.63$ 


\begin{tabular}{|c|c|c|c|}
\hline Variable & $\begin{array}{l}\text { Death }<12 \text { months } \\
(\mathrm{N}=14)\end{array}$ & $\begin{array}{l}\text { Alive }> \\
12 \text { months }(\mathrm{N}=58)\end{array}$ & P-value \\
\hline Age & $81.9+/-8.2$ & $80.2+1-8.9$ & NS \\
\hline Gender & $7 \mathrm{M} / 7 \mathrm{~F}$ & $31 \mathrm{M} / 27 \mathrm{~F}$ & NS \\
\hline DM & 5 & 23 & NS \\
\hline HTN & 14 & 57 & NS \\
\hline STS Score & $0.11+/-0.10$ & $0.10+/-0.05$ & NS \\
\hline Coronary Arteries with Narrowing & $0.93+/-1.27$ & $0.86+/-0.98$ & NS \\
\hline Prior PCI & 2 & 18 & NS \\
\hline Prior CABG & 3 & 17 & NS \\
\hline $\begin{array}{l}\text { Coronary Intervention within } 30 \\
\text { days prior }\end{array}$ & 0 & 5 & $\mathrm{P}<0.05$ \\
\hline PAD & 7 & 28 & NS \\
\hline Carotid Artery Stenosis & 4 & 18 & NS \\
\hline Pre. PPM. AICD & 4 & 9 & NS \\
\hline AVB $1^{\text {st }}$ degree & 3 & 12 & NS \\
\hline Pre-procedure. LBBB & 0 & 4 & NS \\
\hline Post-procedure. LBBB & 5 & 19 & NS \\
\hline New. PPM & 2 & 3 & NS \\
\hline Pre-RBBB & 4 & 9 & NS \\
\hline Pre-Atrial Fibrillation & 2 & 14 & NS \\
\hline Post-Atrial Fibrillation & 3 & 16 & NS \\
\hline $\begin{array}{l}\text { Post procedure Aortic regurgitation } \\
\text { grade }\end{array}$ & $1.1+/-0.9$ & $1.1+/-0.9$ & NS \\
\hline COPD/Lung disease & 8 & 45 & NS \\
\hline Oxygen treatment & 6 & 14 & NS \\
\hline Pre-procedure GFR & $47+/-26$ & $59+/-22$ & NS \\
\hline Post-procedure GFR & $47+/-21$ & $58+/-21$ & NS \\
\hline Contrast (ml) & $92+/-84$ & $111+/-44$ & NS \\
\hline Hemoglobin (Pre, gm/dl) & $11.5+/-2.0$ & $11.5+/-1.6$ & NS \\
\hline Hemoglobin (Discharge, gm/dl) & $9.9+/-0.6$ & $10.5+/-1.2$ & NS \\
\hline Platelets (Pre, $\left.\mathrm{x} 10^{\wedge} 3 / \mathrm{ul}\right)$ & $192+/-52$ & $199+/-114$ & NS \\
\hline Platelets (Discharge, $\mathrm{x} 10^{\wedge} 3 / \mathrm{ul}$ ) & $164+/-74$ & $158+/-76$ & NS \\
\hline Blood transfusion & 7 & 17 & NS \\
\hline Sheath access & 11 & 52 & NS \\
\hline Baseline EF (\%) & $49+/-15$ & $48+/-11$ & NS \\
\hline Post-procedure EF & $55+/-14$ & $52+/ 9$ & NS \\
\hline Pre Aortic Valve Area $\left(\mathrm{cm}^{\wedge} 2\right)$ & $0.71+/-0.15$ & $0.76+/-0.19$ & NS \\
\hline Post Aortic Valve Area $\left(\mathrm{cm}^{\wedge} 2\right)$ & $2.12+/-0.45$ & $2.55+/-2.29$ & NS \\
\hline LVID Pre $(\mathrm{mm})$ & $45.1+/-8.4$ & $46 . .8+/-7.3$ & NS \\
\hline IVSD (mm) & $13.3+/-2.1$ & $12.4+/-2.8$ & NS \\
\hline LVOT diameter (mm) & $21.4+/-1.9$ & $20.7+/-1.9$ & NS \\
\hline LVOT area $\left(\mathrm{mm}^{\wedge} 2\right)$ & $35.8+/-6.6$ & $33.6+/-6.1$ & NS \\
\hline Mean gradient (pre, $\mathrm{mmHg}$ ) & 55.57143 & $50.0+/-11.6$ & NS \\
\hline Mean gradient (post, mmHg) & $14.2+/-8.7$ & $9.9+/-4.1$ & NS \\
\hline Mitral regurgitation (degree $0-4+$ ) & $1.64+/-1.21$ & $1.60+/-1.05$ & NS \\
\hline Mitral stenosis $(\mathrm{N})$ & 1 & 19 & NS $(p=0.054)$ \\
\hline NYHA class (pre) & $3.1+/-0.4$ & $3.3+/-0.6$ & NS \\
\hline NYHA class (post) & $2.0+/-1.1$ & $1.4+/-0.8$ & NS \\
\hline Anticoagulation $(\mathrm{N})$ & 1 & 18 & NS $(p=0.068)$ \\
\hline Antiplatelet (number of drugs) & $1.2+/-0.9$ & $1.6+/-0.6$ & $\mathrm{P}<0.05$ \\
\hline Access site complication (N) & 0 & 4 & NS \\
\hline Groin hematoma $(\mathrm{N})$ & 0 & 3 & NS \\
\hline Duration of hospitalization (days) & $7.6+/-5.5$ & $4.1+/-2.4$ & \\
\hline
\end{tabular}

TABLE 4: Comparison of those with and without early death ( $<12$ months) 
patients required $\mathrm{PCl}$ at or within 30 days prior to the procedure. All transfemoral $(88.9 \%, \mathrm{~N}=64)$ approach patients performed utilizing arterial cut down for sheath access. Combined access site complications rate was $5.6 \%(\mathrm{~N}=4)$. Major and minor access site hematoma rate was $4.2 \%(\mathrm{~N}=3) .33 .3 \%(\mathrm{~N}=24)$ patients required at least 1 unit of red blood cell transfusion. Mean contrast volume was 108 milliliters.

\section{OTHER CLINICAL OUTCOMES}

There was a significant reduction in symptoms to New York Heart Association (NYHA) class I or II at follow up visits. There was a significant increase in Kansas City Cardiomyopathy Questionnaire (KCCQ) points at 30 days $(P<0.02)$ and 12 months $(\mathrm{P}=<0.02)$ follow up. Mean KCCQ before TAVR was 29, which increased to 54 and 53 at 30 days and 1 year respectively. Mean post procedure GFR (55.9 \pm 23.2$)$. Rate of new onset left bundle branch block (LBBB) was $27.7 \%(\mathrm{~N}=20)$. Five patients $(6.9 \%)$ required new permanent pacemaker (PPM) placement. A total of $4(5.5 \%)$ patients developed new onset atrial fibrillation.

\section{ECHOCARDIOGRAPHIC DATA}

Aortic Valve Area (AVA) showed a significant increase as compared to baseline $(P=0.000000001662, t=-$ 6.9), with a mean post procedure AVA of (2.4 CM2 \pm 2.0 ). There was a significant reduction in the mean gradient across aortic valve $(\mathrm{P}=<0.022)$, average post procedure mean gradient $(10.6 \mathrm{mmHg} \pm 5.3)$. Mean post procedure aortic regurgitation including paravalvular and valvular jets was mild. Ejection fraction showed improvement post intervention with mean value of $52 \%$ as compared to $48 \%$ preintervention relation to outcome are shown in Table 4.

\section{DISCUSSION}

We evaluated the high-risk population who underwent TAVR at our institution at the very beginning of our TAVR program. Variable baseline risk factors and elevated pre-procedure Society of Thoracic Surgery (STS) risk score predict increased mortality. 16 Interestingly, in our study the three major predictors of mortality within twelve months were procedural related factors, however no statistical significance was noted possibly due to small sample size. Not surprisingly, two out of three elements were renal related. Acute Kidney Injury (AKI) is a frequently encountered complication post TAVR. ${ }^{17,18}$ Several predictors of AKI have been studied..$^{19}$ Pre existing chronic kidney disease, respiratory failure, blood transfusion, previous stroke, frequent intraprocedural valve reposition, periprocedural embolization, hemodynamic instability associated with rapid pacing, and use of contrast medium were strong predictors for acute kidney injury. ${ }^{18,20}$

In our study contrast media volume was a predictor for increased 12 months mortality. Nevertheless, limiting contrast use is a priority during TAVR; complexity of cases, however, may mandate the opposite. Interestingly, a meta-analysis of four cohort studies which included 891 TAVR patients did not show a significant association between contrast media volume and risk of AKI, ${ }^{21}$ however the small number of the included studies is a limitation of the analysis. Thus further studies may be warranted to evaluate whether contrast media volume alone without $A K I$ is a potential independent surrogate for increase mortality post TAVR. New onset AKI demonstrated worse short and long prognostic impacts among TAVR population. According to a meta-analysis of 5,971 patients, post procedure AKI was associated with increased all cause and cardiovascular mortality early and at 12 months. ${ }^{22}$ RenalGuard system utilizing furosemide induced diuresis with matched isotonic saline may be an effective tool in reducing incidence of post TAVR $\mathrm{AKI}^{23,24}$

Valve designs and procedural techniques have evolved significantly over the recent period. Lower valve profile has enhanced valve deliverability and reduced complications. Sheath size has decreased significantly from 24 French $(\mathrm{Fr}$ ) to 14-16 Fr thus reducing the need for arterial cut down and access site complications. Moreover, addition of an external skirt to the balloon expandable valves (Sapien XT, Sapien 3) reduced paravalvular regurgitation. ${ }^{25}$ In our sample only four patients demonstrated access site complications, however majority of the valves were early generation with higher profile and required arterial cut down in nearly all of the 
transfemoral cases. Despite using early generation valves in the majority of cases, the mean degree of paravalvular regurgitation was mild.

Thirty days and 12 months stokes rates were $2.8 \%(\mathrm{~N}=2)$, and $8.3 \%(\mathrm{~N}=6)$ respectively. Our 30 days rate is lower than results reported in large prospective cohorts ( $2.8 \%$ vs. $5 \%$ in the PARTNER trial), while our 12 months results are comparable (8.3 vs. 7.8). ${ }^{3,4}$ Neurological events post TAVR are classified as early within first 24-48 hours (procedural related), delayed between 2-30 days, and late after 30 days (patient and disease related factors). ${ }^{26}$ Small aortic valve area, balloon post dilatation, and atrial fibrillation are associated with increased incidence of early cerebrovascular accidents (CVAs). Chronic atrial fibrillation, prior cerebrovascular disease, and transapical approach are some predictors of late CVAs. ${ }^{27}$ Currently there is controversy about the benefit of embolic protection devices, however recent meta-analysis of randomized control trials demonstrated promising role in stroke reduction; future large studies may answer this question. ${ }^{28}$

Sedation technique during the procedure has evolved since the advent of TAVR. Initially the procedure was only done under general anesthesia, as is the case in our early sample. However, currently most of the TAVR in our institution are performed under conscious sedation. Hence ICU hours and cost of care have significantly reduced by using conscious sedation. ${ }^{29}$ Finally, we have noticed that mono-antiplatelet therapy (MAPT) in our population was a strong predictor of increased 12 months mortality. The current consensus is utilizing heparin during the procedure and dual antiplatelet therapy (DAPT) for 6 months following the implantation of the valve..$^{30}$ Interestingly, a large meta-analysis showed conflicting results regarding dual versus single antiplatelet therapy. ${ }^{31,32}$ Analysis of nine studies, which included 7991 patients, demonstrated a significant reduction in mortality and a slight benefit in stroke prevention without increase in major bleeding, as compared to MAPT alone. ${ }^{31}$ Addition of oral anticoagulation to MAPT did not show any benefit when it compared to DAPT in the same meta-analysis. However, another meta-analysis of six studies which included 840 patients showed increased bleeding risk with DAPT, with no reduction in mortality, stroke, or myocardial infarction..$^{32}$ Hence, despite its increasing use, the optimal antiplatelet management of patients undergoing TAVR remains uncertain. Given our small sample size, further multicenter studies are warranted to delineate the association between MAPT and mortality risk among TAVR population.

In conclusion, we found that post procedure GFR, less number of antiplatelet agents post procedure, and contrast volume may predict mortality within first 12 months post TAVR. Further studies focused on the above factors may be warranted.

\section{AUTHOR AFFILIATIONS}

1. Marshall University Joan C. Edwards School of Medicine, Huntington, West Virginia

2. Huntington Internal Medicine Group, Huntington, West Virginia

\section{REFERENCES}

1. Franzone A, Piccolo R, Siontis GC, Lanz J, Stortecky S, Praz F, Roost E, Vollenbroich R, Windecker S, Pilgrim T. Transcatheter aortic valve replacement for the treatment of pure native aortic valve regurgitation: a systematic review. JACC Cardiovasc Interv. 2016;9:2308-2317.

2. Leon MB, Smith CR, Mack M, Miller DC, Moses JW, Svensson LG, Tuzcu EM, Webb JG, Fontana GP, Makkar RR, Brown DL, Block PC, Guyton RA, Pichard AD, Bavaria JE, Herrmann HC, Douglas PS, Petersen JL, Akin JJ, Anderson WN, Wang D, Pocock S, Investigators PT. Transcatheter aorticvalve implantation for aortic stenosis in patients who cannot undergo surgery. N Engl J Med. 2010;363:1597-607.

3. Adams DH, Popma JJ, Reardon MJ. Transcatheter aortic-valve replacement with a self-expanding prosthesis. N Engl J Med. 2014;371:967-8.

4. Leon MB, Smith CR, Mack MJ, Makkar RR, Svensson LG, Kodali SK, Thourani VH, Tuzcu EM, Miller DC, Herrmann HC, Doshi D, Cohen DJ, Pichard AD, Kapadia S, Dewey T, Babaliaros V, Szeto WY, Williams MR, Kereiakes D, Zajarias A, Greason KL, Whisenant BK, Hodson RW, Moses JW, Trento A, Brown DL, Fearon WF, Pibarot P, Hahn RT, Jaber WA, Anderson WN, Alu MC, Webb 
JG, Investigators P. Transcatheter or surgical aortic-valve replacement in intermediate-risk patients. N Engl J Med. 2016;374:1609-20.

5. Khitan Z, Shapiro AP, Shah PT, Sanabria JR, Santhanam P, Sodhi K, Abraham NG, Shapiro JI. Predicting adverse outcomes in chronic kidney disease using machine learning methods: data from the modification of diet in renal disease. Marshall Journal of Medicine. 2017;3:67-79.

6. Gullo CA, McCarthy MJ, Shapiro JI, Miller BL. Predicting medical student success on licensure exams. Med Sci Educ. 2015;25:447-453.

7. Chen T, Cao Y, Zhang Y, Liu J, Bao Y, Wang C, Jia W, Zhao A. Random forest in clinical metabolomics for phenotypic discrimination and biomarker selection. Evid Based Complement Alternat Med. 2013;2013:298183.

8. Khondoker MR, Bachmann TT, Mewissen M, Dickinson P, Dobrzelecki B, Campbell CJ, Mount AR, Walton AJ, Crain J, Schulze H, Giraud G, Ross AJ, Ciani I, Ember SW, Tlili C, Terry JG, Grant E, McDonnell N, Ghazal P. Multi-factorial analysis of class prediction error: estimating optimal number of biomarkers for various classification rules. J Bioinform Comput Biol. 2010;8:945-65.

9. Zhang Z. A gentle introduction to artificial neural networks. Ann Transl Med. 2016;4:370.

10. Tsiliki G, Munteanu CR, Seoane JA, FernandezLozano C, Sarimveis $H$, Willighagen EL. RRegrs: an $R$ package for computer-aided model selection with multiple regression models. J Cheminform. 2015;7:46.

11. Liu R, Li X, Zhang W, Zhou HH. Comparison of nine statistical model based warfarin pharmacogenetic dosing algorithms using the racially diverse International Warfarin Pharmacogenetic Consortium Cohort Database. PLoS One. 2015;10:e0135784.

12. Robin $X$, Turck N, Hainard A, Tiberti N, Lisacek F, Sanchez JC, Muller M. pROC: an open-source package for $\mathrm{R}$ and $\mathrm{S}+$ to analyze and compare ROC curves. BMC Bioinformatics. 2011;12:77.

13. Emir B, Johnson K, Kuhn M, Parsons B. Predictive modeling of response to pregabalin for the treatment of neuropathic pain using 6-week observational data: a spectrum of modern analytics applications. Clin Ther. 2017;39:98-106.

14. Hengl T, Mendes de Jesus J, Heuvelink GB, Ruiperez Gonzalez M, Kilibarda M, Blagotic A, Shangguan W, Wright MN, Geng X, Bauer-
Marschallinger $B$, Guevara MA, Vargas $R$, MacMillan RA, Batjes NH, Leenaars JG, Ribeiro E, Wheeler I, Mantel S, Kempen B. SoilGrids250m: Global gridded soil information based on machine learning. PLoS One. 2017;12:e0169748.

15. Gallo S, Hazell T, Vanstone CA, Agellon S, Jones G, L'Abbe M, Rodd C, Weiler HA. Vitamin D supplementation in breastfed infants from Montreal, Canada: 25-hydroxyvitamin D and bone health effects from a follow-up study at 3 years of age. Osteoporos Int. 2016.

16. Wendt $D$, Thielmann $M$, Kahlert $P$, Kastner $S$, Price V, Al-Rashid F, Patsalis P, Erbel R, Jakob $\mathrm{H}$. Comparison between different risk scoring algorithms on isolated conventional or transcatheter aortic valve replacement. Ann Thorac Surg. 2014;97:796-802.

17. Thongprayoon C, Cheungpasitporn W, Srivali N, Kittanamongkolchai W, Greason KL, Kashani KB. Incidence and risk factors of acute kidney injury following transcatheter aortic valve replacement. Nephrology (Carlton). 2016;21:1041-1046.

18. Crowhurst JA, Savage M, Subban V, Incani A, Raffel OC, Poon K, Murdoch D, Saireddy R, Clarke A, Aroney C, Bett N, Walters DL. Factors contributing to acute kidney injury and the impact on mortality in patients undergoing transcatheter aortic valve replacement. Heart Lung Circ. 2016;25:282-9.

19. Marbach JA, Feder J, Yousef A, Ramirez FD, Simard T, DiSanto P, Russo JJ, Boland P, Labinaz M, Glover C, Dick A, Hibbert B. Predicting acute kidney injury following transcatheter aortic valve replacement. Clin Invest Med. 2017;40:E243-E251.

20. Ram P, Mezue K, Pressman G, Rangaswami J. Acute kidney injury post-transcatheter aortic valve replacement. Clin Cardiol. 2017;40:13571362.

21. Thongprayoon C, Cheungpasitporn W, Podboy AJ, Gillaspie EA, Greason KL, Kashani KB. The effects of contrast media volume on acute kidney injury after transcatheter aortic valve replacement: a systematic review and metaanalysis. J Evid Based Med. 2016;9:188-193.

22. Gargiulo G, Sannino A, Capodanno D, Perrino C, Capranzano P, Barbanti M, Stabile E, Trimarco B, Tamburino C, Esposito G. Impact of postoperative acute kidney injury on clinical outcomes after transcatheter aortic valve 
implantation: A meta-analysis of 5,971 patients. Catheter Cardiovasc Interv. 2015;86:518-27.

23. Putzu A, Boscolo Berto M, Belletti A, Pasotti E, Cassina T, Moccetti T, Pedrazzini G. Prevention of contrast-induced acute kidney injury by furosemide with matched hydration in patients undergoing interventional procedures: $a$ systematic review and meta-analysis of randomized trials. JACC Cardiovasc Interv. 2017;10:355-363.

24. Barbanti $M$, Gulino $S$, Capranzano $P$, Imme $S$, Sgroi C, Tamburino C, Ohno Y, Attizzani GF, Patane M, Sicuso R, Pilato G, Di Landro A, Todaro D, Di Simone E, Picci A, Giannetto G, Costa G, Deste W, Giannazzo D, Grasso C, Capodanno $D$, Tamburino C. Acute kidney injury with the RenalGuard System in patients undergoing transcatheter aortic valve replacement: The PROTECT-TAVI Trial (prophylactic effect of furosemide-induced diuresis with matched isotonic intravenous hydration in transcatheter aortic valve implantation). JACC Cardiovasc Interv. 2015;8:1595-604.

25. Cribier $A$. The development of transcatheter aortic valve replacement (TAVR). Glob Cardiol Sci Pract. 2016;2016:e201632.

26. Hecker F, Arsalan M, Walther T. Managing stroke during transcatheter aortic valve replacement. Interv Cardiol. 2017;12:25-30.

27. Mastoris I, Schoos MM, Dangas GD, Mehran R. Stroke after transcatheter aortic valve replacement: incidence, risk factors, prognosis, and preventive strategies. Clin Cardiol. 2014;37:756-64.

28. Wang N, Phan K. Cerebral protection devices in transcatheter aortic valve replacement: a clinical meta-analysis of randomized controlled trials. J Thorac Dis. 2018;10:1927-1935.

29. Toppen $W$, Johansen $D$, Sareh S, Fernandez J, Satou N, Patel KD, Kwon M, Suh W, Aksoy O, Shemin RJ, Benharash P. Improved costs and outcomes with conscious sedation vs general anesthesia in TAVR patients: Time to wake up? PLoS One. 2017;12:e0173777.

30. Nishimura RA, Otto CM, Bonow RO, Carabello BA, Erwin JP, 3rd, Guyton RA, O'Gara PT, Ruiz CE, Skubas NJ, Sorajja P, Sundt TM, 3rd, Thomas JD and American College of Cardiology/American Heart Association Task Force on Practice G. 2014 AHA/ACC guideline for the management of patients with valvular heart disease: a report of the American College of Cardiology/American Heart Association Task Force on Practice Guidelines. J Am Coll Cardiol. 2014;63:e57-185.

31. Verdoia M, Barbieri L, Nardin M, Suryapranata $H$, De Luca G. Dual versus single antiplatelet regimen with or without anticoagulation in transcatheter aortic valve replacement: indirect comparison and meta-analysis. Rev Esp Cardiol (Engl Ed). 2018;71:257-266.

32. Raheja H, Garg A, Goel S, Banerjee K, Hollander G, Shani J, Mick S, White J, Krishnaswamy A, Kapadia S. Comparison of single versus dual antiplatelet therapy after TAVR: A systematic review and meta-analysis. Catheter Cardiovasc Interv. 2018. 